\title{
Scientist commercialization as conduit of knowledge spillovers
}

\author{
David B. Audretsch • T. Taylor Aldridge
}

Received: 16 June 2008 / Accepted: 3 March 2009 / Published online: 8 April 2009

(C) Springer-Verlag 2009

\begin{abstract}
This paper examines how institutional, locational and individual characteristics of university scientists influence patent inventions. The paper illustrates why and how some scientists combine scientific and commercial creativity in the context of their regional location and the particular type of institution where the scientist is employed. Using a dataset of 1,683 individual scientists, over a 7-year period, the paper estimates the impact of their patenting propensity. The paper uses the Carnegie Classification of Universities, location and scientists human capital and applies a logit analysis is to determine which aspects affect a scientist's propensity to patent.
\end{abstract}

\section{JEL Classification L26}

\section{Introduction}

In his path breaking book, The Rise of the Creative Class, Florida (2002) identifies three types of creativity - artistic creativity, scientific creativity, and entrepreneurial creativity. This paper focuses on the intersection of two of these types of creativity — scientific and entrepreneurial—and examines the extent to which they can occur within the same analytical unit of observation, in this case the scientist. Thus, this paper examines the extent to which scientists are able to combine scientific creativity with entrepreneurial creativity.

Why and will scientists decide to combine their scientific creativity with commercial creativity? The answers to this question are important to institutions and scientists engaged in research. The New Endogenous Growth models and theories highlight the central role that investments in science and research play in generating economic

D. B. Audretsch $(\varangle)$. T. T. Aldridge

Max Planck Institute of Economics, Jena, Germany

e-mail: audretsch@econ.mpg.de 
growth (Romer 1986; Lucas 1993). But more recently, public policy makers, ranging from local communities, to states and even entire countries have pointed out that such investments in knowledge and research do not automatically spill over into commercialized new products and innovations. Rather, what Acs et al. (2009) and Audretsch et al. (2005) term as the knowledge filter effectively impedes the spillover and commercialization of investments in knowledge, thereby limiting the rate of employment creation and economic growth returns accruing from public and private investments in science and research. In the presence of a high knowledge filter, investments in science and research do not automatically spill over and become commercialized, resulting in vigorous rates of economic growth and employment generation, as assumed in models of endogenous growth. The combination of high investments in science and research but low rates of economic growth and employment generation led first to what was termed as the Swedish Paradox and somewhat later adapted by European Commission as The European Paradox. Audretsch et al. (2005) and Acs et al. (2009) identify activities that involve the commercialization of science and research as the Missing Link in the process of economic growth. In the absence of scientist commercialization of research, investments in science and research will not generate an adequate rate economic growth and job creation returns.

The purpose of this study is to understand why some scientists choose to combine commercialization creativity with scientific creativity while others do not. We do this by analyzing the propensity of scientists funded by grants from the National Cancer Institute (NCI) to commercialize their research. The results of this study suggest that scientists receiving NCI funding have a high propensity to commercialize their research. However, both characteristics specific to the scientist, such as her human capital and reputation as well as institutional and environmental factors, such as the regional and university context within which she works influence the propensity for a scientist to commercialize her research.

\section{Combining scientific and entrepreneurial creativity}

Why will a scientist choose to combine her scientific creativity with entrepreneurial creativity? A number of theories and hypotheses have posited why some scientists choose to commercialize research while others do not, and some compelling insights have been garnered through previous empirical studies. These include the scientist life-cycle, which highlights the role of reputation, the knowledge production function, which highlights the role of scientific human capital and resources, and the regional and university contexts, which highlight the role of geographically bounded spillovers and institutional incentives.

A large literature has emerged focusing on what has become known as the appropriability problem. The underlying issue revolves around how firms which invest in the creation of new knowledge can best appropriate the economic returns from that knowledge (Arrow 1962). Audretsch (1995) proposed shifting the unit of observation away from exogenously assumed firms to individuals - agents with endowments of new economic knowledge. When the lens is shifted away from the firm to the individual as the relevant unit of analysis, the appropriability issue remains, but the question 
becomes: "How can scientists with a given endowment of new knowledge best appropriate the returns from that knowledge?" Levin and Stephan (1991) suggest that the answer is, it depends-it depends on both the career trajectory as well as the stage of the life-cycle of the scientist.

The university or academic career trajectory encourages and rewards the production of new scientific knowledge. Thus, the goal of the scientist in the university context is to establish priority. This is done most efficiently through publication in scientific journals (Audretsch and Stephan 2000). By contrast, with a career trajectory in the private sector, scientists are rewarded for the production of new economic knowledge, or knowledge which has been commercialized in the market, but not necessarily new scientific knowledge per se. In fact, scientists working in industry are often discouraged from sharing knowledge externally with the scientific community through publication. As a result of these differential incentive structures, industrial and academic scientists develop distinct career trajectories.

The appropriability question confronting academic scientists can be considered in the context of the model of scientist human capital over the life-cycle. Scientist lifecycle models suggest that early in their careers scientists invest heavily in human capital in order to build a scientific reputation (Levin and Stephan 1991). In the later stages of their career, the scientist trades or cashes in this reputation for economic return. Thus, early in her career, the scientist invests in the creation of scientific knowledge in order to establish a reputation that signals the value of that knowledge to the scientific community.

With maturity, scientists seek ways to appropriate the economic value of the new knowledge. Thus, academic scientists may seek to commercialize their scientific research within a life-cycle context. The life-cycle model of the scientist implies that, ceteris paribus, scientist reputation should play a role in the decision to commercialize.

An implication of the knowledge production function formalized by Griliches (1979) is that those scientists with a greater research and scientific prowess have the capacity for generating a greater scientific output. But how does scientific capability translate into observable characteristics that can promote or impede commercialization efforts? Because the commercialization of scientific research is particularly risky and uncertain (Audretsch and Stephan 2000), a strong scientific reputation, as evidenced through vigorous publication and formidable citations, provides a greatly valued signal of scientific credibility and capability to any anticipated commercialized venture or project. This suggests a hypothesis, linking measures of the quality of the scientist, or her scientific reputation as measured by citations and publications, to commercialization.

Scientist location can influence the decision to commercialize for two reasons. First, as Jaffe (1989), Audretsch and Feldman (1996), Jaffe et al. (1993) and Glaeser et al. (2002) show, knowledge tends to spill over within geographically bounded regions. This implies that scientists working in regions with a high level of investments in new knowledge can more easily access and generate new scientific ideas. This suggests that scientists working in knowledge clusters should tend to be more productive than their counterparts who are geographically isolated. As Glaeser et al. (1992, p. 1126) have observed, "Intellectual breakthroughs must cross hallways and streets more easily than oceans and continents." 
A second component of externalities involves not the technological knowledge, but rather behavioural knowledge. As Bercovitz and Feldman (2004) show for a study based on the commercialization activities of scientists at Johns Hopkins and Duke University, the likelihood of a scientist engaging in commercialization activity, which is measured as disclosing an invention, is shaped based on the commercialization behaviour of the doctoral supervisor in the institution where the scientist was trained, as well as the commercialization behaviour and attitudes exhibited by the chair and peers at the relevant department.

Thus, the locational and institutional contexts can influence the propensity for scientists to engage in commercialization activities by providing access to spatially bounded knowledge spillovers and by shaping the institutional setting and behavioural norms and attitudes towards commercialization.

\section{Measurement issues}

The commercialization activity of university scientists was measured by starting with those scientists that were awarded a research grant by the National Cancer Institute between 1998 and 2002. Of those research grant awards, the largest 20 percent, which included 1,693 scientist awardees, were taken to form the database used in this study. The National Cancer Institute (NCI) awarded a total of $\$ 5,350,977,742$ to the top 1,693 scientists in the United States from 1998 to 2002.

Because the focus of this paper is on the propensity for scientists to commercialize their research, commercialization must be operationalized and measured. The most common measure of commercialization of research is patents. Thus, the propensity for NCI recipient scientists to patent was analyzed by obtaining patent data from the United States Patent and Trade Office (USPTO). The patent database spans 19752004. The inventor patent data included identification of the patent number of the invention, the name and address of the inventor, and the inventor sequence number.

Figure 1 shows that the geographic distribution of patentees varied both across regions as well as by gender. In some regions, such as New York, Mid-Atlantic, the North West and Texas, the propensity for females to patent exceeded that of their male colleagues. By contrast, in other regions, such as California, New England and the Great Lakes, male scientists exhibited a greater propensity to patent.

Gender also clearly played a role in a number of other dimensions. For example, Fig. 2 shows that the mean amount of the NCI grant was considerably greater for male scientists who patented than for their female counterparts.

\section{Estimation of a logit model}

To shed light on the question, "Why do some scientists patent their scientific research while others do not?" a logit model was estimated for the unit of observation of the scientist identified in the NCI database where the dependent variable takes on the value of one if she has patented over the time period 1998-2004 and zero if she did not.

The previous section suggests five different types of factors shaping the decision by a scientist to commercialize her research-resources, personal characteristics, scien- 


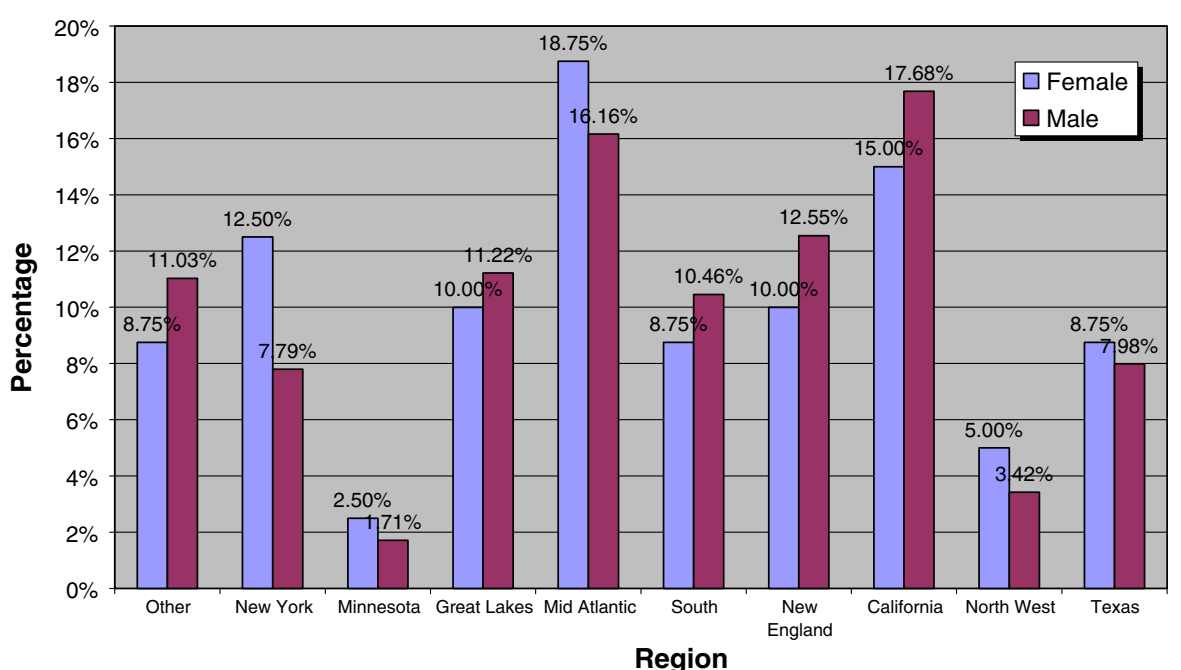

Fig. 1 Patents by region and gender

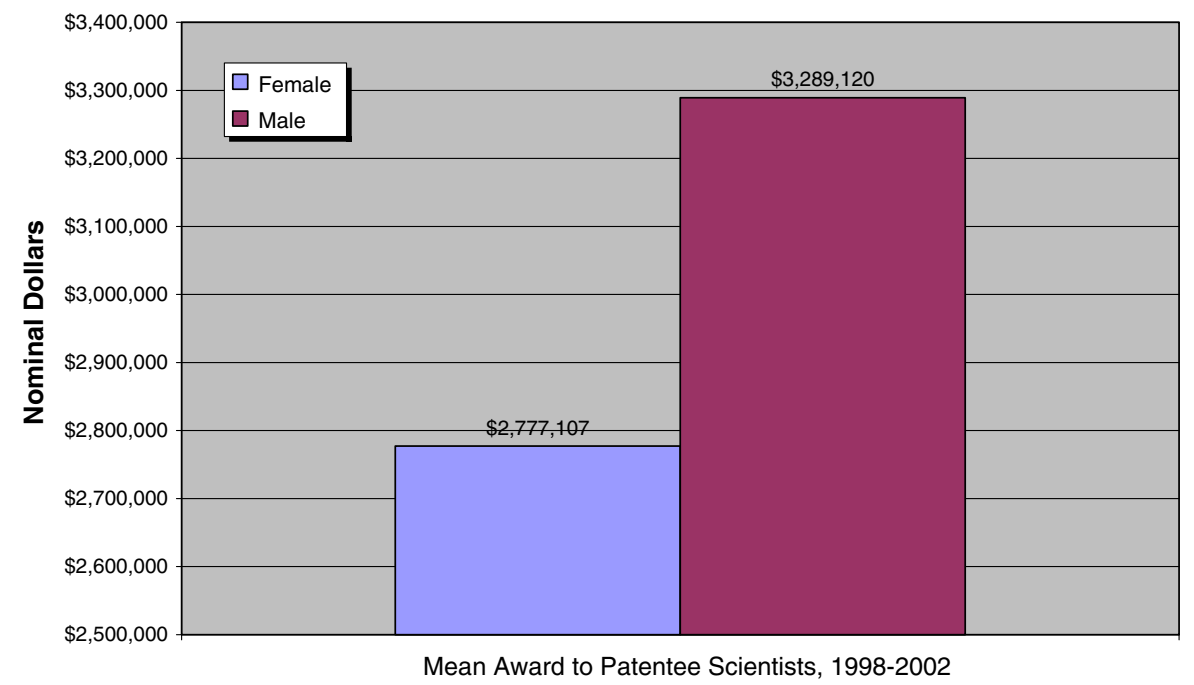

Fig. 2 NCI Grant award by gender for patenting scientists

tific human capital, nature of the university, and location. These factors are empirically operationalized through the following measures:

Award amount. This variable is the mean total NCI awarded to the scientist between 1998 and 2002. The award amount was obtained from the original NCI award excel sheet. If external funding of scientific research is conducive to commercialization, a positive coefficient of the Award Amount would be expected.

Male. This is a dummy variable assigned the value of one for males $(1,310)$ of the overall 1,693 included in the NCI database. The gender of each scientist was obtained 
by "Googling" their names. The estimated coefficient will reflect whether the gender of the scientist influences the propensity to commercialize research.

Location. Ten different locational dummy variables were created taking on the value of one for Texas, California, New York, Minnesota, Great Lakes (Ohio, Indiana, Illinois, Michigan and Wisconsin), North West (Oregon and Washington), New England (Maine, Vermont, New Hampshire, Connecticut, Rhode Island and Massachusetts), South Atlantic (Virginia, North Carolina, South Carolina, Georgia and Florida), Mid Atlantic (Washington DC, Maryland, Pennsylvania), and other (Arizona, Alabama, New Mexico, Colorado, Nebraska, Hawaii and Iowa.) Those regions which tend to have greater investments in research and science, and also have developed a culture more encouraging university and scientist commercialization, such as California and New England, might be expected to have a positive coefficient.

\section{University type}

- Ivy League. A dummy variable was created taking on the value of one for all scientists employed at Brown University, Cornell University, Columbia University, Dartmouth College, Harvard University, Princeton University, the University of Pennsylvania and Yale University.

- Public Universities. A dummy variable was created taking on the value of one for scientists employed at public universities and zero otherwise. Because they are at least partially financed by the public, state universities tend to have a stronger mandate for outreach and commercialization of research. This may suggest a positive coefficient.

- Carnegie classifications. The Carnegie Classification of Universities (2000 edition) provides a comprehensive study classifying universities by types of degree offered. Each type of institution is defined according to the types and numbers of degrees offered in different fields. The categories are

1. Special Medical Institution (graduate only that specializes in medical degrees (i.e. doctors and nurses)

2. Research Intensive University (grants doctoral degrees in three fields and fewer than 50 annually)

3. Research Extensive University (grants doctoral degrees in more than three fields and more degrees than 50 annually)

4. Bachelors and Masters College (grants only BA/BS and masters degrees but no Ph.D.s)

5. Associate's College (2 year institution)

\subsection{Scientist human capital}

- Citations. A specific computer program was designed to measure the citations of the 1,693 scientists through the "Expanded Science Citation Index." A higher number of citations reflect a higher level of human capital and scientific reputation (Audretsch and Stephan 2000). A positive coefficient would reflect that the likelihood of commercialization is greater for more productive scientists. 
Table 1 Logit results for scientist patents

\begin{tabular}{|c|c|c|c|c|}
\hline & (1) & (2) & (3) & (4) \\
\hline Male & $0.884(6.33)^{* *}$ & $0.896(6.43)^{* *}$ & $0.878(6.27)^{* *}$ & $0.878(6.29)^{* *}$ \\
\hline Medical University & $0.248(1.52)$ & - & $0.228(1.16)$ & - \\
\hline Extensive University & - & $0.020(0.14)$ & - & - \\
\hline Intensive University & $-0.140(-0.63)$ & - & $-0.171(-0.77)$ & - \\
\hline Star scientist & $0.298(1.75)^{*}$ & - & - & - \\
\hline Citations & - & - & $0.643(2.97)^{* *}$ & $0.644(2.96)^{* *}$ \\
\hline Papers published & - & $-0.010(-0.05)$ & - & - \\
\hline NCI total award & $0.992(0.951)$ & $-0.342(-0.02)$ & $-0.297(-0.18)$ & $-0.003(-0.19)$ \\
\hline Public Institutions & $-0.182(-1.44)$ & $-0.202(-1.62)$ & $-0.164(-1.29)$ & $-0.209(-1.69)^{*}$ \\
\hline Ivy League & $0.219(1.13)$ & $0.171(0.89)$ & $0.227(1.16)$ & - \\
\hline Texas & - & $0.191(0.438)$ & $-0.593(-2.01)^{* *}$ & $0.259(1.11)$ \\
\hline North West & $-0.361(-1.29)$ & $-0.406(-1.48)$ & $-0.966(-3.32)^{* *}$ & $-0.283(-0.97)$ \\
\hline California & $0.597(3.00)^{* * *}$ & $0.485(2.80)^{* *}$ & - & $0.587(2.97)^{* *}$ \\
\hline New England & $0.463(0.048)^{* *}$ & $0.375412(1.73)^{*}$ & $-0.153(-0.67)$ & $0.526(2.31)^{* *}$ \\
\hline South & $0.134(0.64)$ & - & $0.472(-2.21)^{* *}$ & $0.169(0.78)$ \\
\hline Mid Atlantic & $0.090(0.47)$ & $-0.137(-1.57)$ & $-0.504(-2.55)^{* *}$ & $0.184(0.94)$ \\
\hline Great Lakes & - & - & $-0.666(-3.27)^{* *}$ & - \\
\hline Minnesota & $-0.659(-1.79)^{* *}$ & $-0.580(-1.57)$ & $-1.264(-3.23) * *$ & $-0.510(-1.35)$ \\
\hline New York & $-0.162(-0.70)$ & $-0.211(-0.95)$ & $-0.741(-3.14)^{* *}$ & $-0.062(-0.27)$ \\
\hline Other & & & $-0.637(-3.03)^{* *}$ & $0.033(0.874)$ \\
\hline Intercept & $-1.388(-6.41) * *$ & $-1.286(-5.44) * *$ & $-0.828(-3.97)^{* *}$ & $-1.432(-6.82) * *$ \\
\hline Pseudo $R^{2}$ & 0.04 & 0.037 & 0.043 & 0.041 \\
\hline$>$ Chi-squared & 0.000 & 0.000 & 0.000 & 0.000 \\
\hline Sample size & 1,683 & 1,683 & 1,683 & 1,683 \\
\hline
\end{tabular}

$t$-Statistic in brackets

* Statistically significant at the two-tailed test for 90 percent level of confidence

** Statistically significant at the two-tailed test for 95 percent level of confidence

- Publications. A specific computer program was designed to measure the publications of the scientist, which should also reflect the level of human capital and scientific reputation (Audretsch and Stephan 2000).

- Star scientist. A scientist is classified as being a star if she is in the top ten percent of publications. A dummy variable was created taking on the value of one for those scientists with a star classification and zero otherwise. Star scientists may be able to attract resources for commercialization, suggesting a positive coefficient (Audretsch and Stephan 1996).

The results from estimating the logit model using the patent measure for scientist commercialization are provided in Table 1.

The various measures of scientist human capital, or scientist quality, are highly correlated and therefore including them in the same estimated model may result in multicollinearity. Thus, the first column presents results when the measure of star 
scientist is used, while the second column includes the measure of publications, and the third and fourth column citations. As the positive and statistically significant coefficient of star scientist suggests, those scientists with a prolific publication record tend to have a higher propensity to commercialize research through patents. Similarly, those scientists with greater citations also have a greater likelihood of filing for a patent.

There is also considerable statistical evidence suggesting that the gender of a scientist influences the likelihood of commercialization in the form of patents. In particular, being a male will elevate the propensity for a scientist to patent. The evidence concerning the impact on university type on the patenting activities of scientists is weaker and more ambiguous. There is at least some evidence suggesting that being employed in a public university may actually reduce the likelihood of a scientist patenting. Finally, the region in which the scientist is located apparently influences her propensity to patent. In particular, those scientists located in California and New England exhibit a greater likelihood of patenting, even after controlling for the other main factors, such as scientist quality and gender.

\section{Conclusions}

Globalization has triggered a shift in the comparative advantage of leading developed countries away from the factor of capital and towards knowledge. For the factor of knowledge to be effective in generating employment, economic growth and international competitiveness, it must spill over to become commercialized. As Acs and Audretsch (2003) emphasize such knowledge spillovers are not automatic and cannot be assumed to exist. Thus, in terms of Richard Florida's insights about creativity, investments in scientific creativity need to be combined with commercial creativity to facilitate the spillover of such knowledge that can ultimately contribute to economic growth. Such scientific creativity can be combined with commercial creativity by scientists who choose to commercialize their research.

This paper has identified why some scientists choose to combine scientific and commercial creativity while others do not. In particular, the human capital and reputation of the scientist play an important role, as does the context, in terms of regional location and particular type of institution where the scientist is employed. The evidence suggests that it is those scientists with the greatest amount of knowledge who have a higher propensity to commercialize their research. However, such scientist commercialization is conditioned by both the type of university as well as the region.

\section{References}

Acs Z, Audretsch D (2003) Handbook of entrepreneurship research. Kluwer Academic Publishers, Dordretcht

Acs ZJ, Audretsch DB, Braunerhjelm P, Carlsson B (2009) The knowledge spillover theory of entrepreneurship. Small Bus Econ 32(1): 15-30

Audretsch D, Keilbach M, Lehmann E (2005) The knowledge spillover theory of entrepreneurship and technological diffusion. In: Libecap GD (ed) University entrepreneurship and technological transfer: process, design and intellectual property. Advances in the study of entrepreneurship, innovation and economics growth, vol. 16. Elsevier, Amsterdam, pp 69-91 
Audretsch DB (1995) Innovation and industry evolution. MIT Press, Cambridge

Audretsch DB, Stephan PE (2000) The economics of science and innovation, vol I, II. Edward Elgar, Cheltenham

Audretsch DB, Feldman MP (1996) R\&D spillovers and the geography of innovation and production. Am Econ Rev 86(3):630-640

Audretsch DB, Stephan PE (1996) Company-scientist locational links: the case of biotechnology. Am Econ Rev 86(3):641-652

Arrow KJ (1962) Economic welfare and the allocation of resources for invention. In: Nelson RR (ed) The rate and direction of inventive activity. Princeton University Press, Princeton, pp 609-626

Bercovitz J, Feldman M (2004) Academic entrepreneurs: social learning and participation in university technology transfer (work in progress)

Florida R (2002) The rise of the creative class. Basic Books, New York

Glaeser E, Kallal H, Scheinkman J, Shleifer A (1992) Growth of cities. J Polit Econ (100):1126-1152

Glaeser EL, Laibson D, Sacerdot B (2002) An economic approach to social capital. Econ J 112(483):F437F458, Features (Nov., 2002)

Griliches Z (1979) Issues in assessing the contribution of R\&D to productivity growth. Bell J Econ (10):92116

Jaffe AB (1989) Real effects of academic research. Am Econ Rev 79(5):957-970

Jaffe A, Trajtenberg M, Henderson R (1993) Geographic localization of knowledge spillovers as evidenced by patent citations. Q J Econ (63):577-598

Levin SG, Stephan PE (1991) Research productivity over the life cycle: evidence for academic scientists. Am Econ Rev 81(4):114-132

Lucas RE Jr (1993) Making a miracle. Econometrica (61):251-272

Romer P (1986) Increasing returns and long-run growth. J Polit Econ 94(5):1002-1037. doi:10.1086/261420 